\title{
Staphylococcal Enterotoxin C
}

National Cancer Institute

\section{Source}

National Cancer Institute. Staphylococcal Enterotoxin C. NCI Thesaurus. Code C1085.

Staphylococcal enterotoxin C. A superantigen and member of a family of genetically related proteins produced by Staphylococcus aureus and Streptococcus pyogenes. An extremely potent activator of T lymphocytes when presented on MHC class II antigens. 